Supporting information

\title{
Lysozyme adsorption on different functionalized MXenes: a multi-scale simulation study
}

Daohui Zhao ${ }^{*}$, Chu Huang ${ }^{1}$, Xuebo Quan ${ }^{2}$, Libo Li ${ }^{2}$, Yuqing Wang ${ }^{1}$, Jian Zhou ${ }^{2 *}$

${ }^{1}$ Hubei Collaborative Innovation Center for Advanced Organic Chemical Materials, Ministry of Education Key Laboratory for the Synthesis and Application of Organic Functional Molecules, School of Chemistry and Chemical Engineering, Hubei University, Wuhan 430062, P.R. China

${ }^{2}$ School of Chemistry and Chemical Engineering, Guangdong Provincial Key Lab for Green Chemical Product Technology, South China University of Technology, Guangzhou 510640, P. R. China 


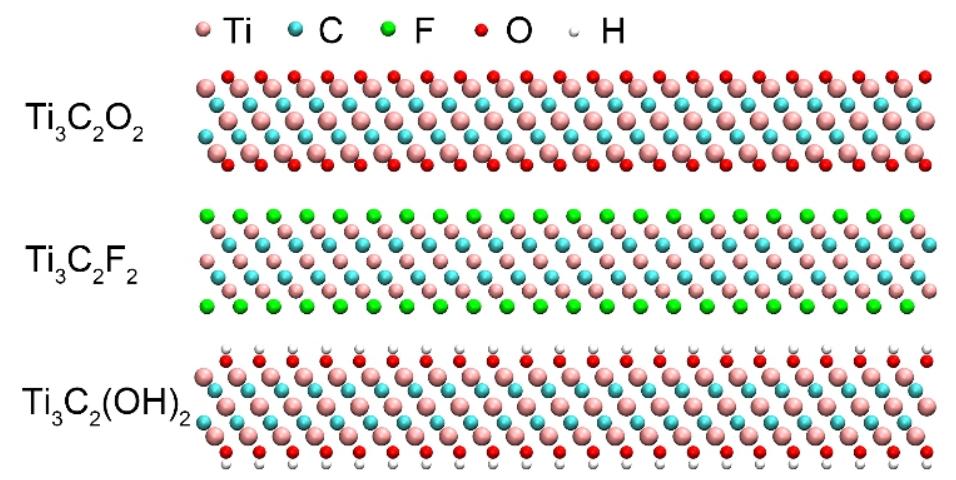

Figure S1. Schematic diagram of the atomistic structures of $\mathrm{Ti}_{3} \mathrm{C}_{2} \mathrm{~T}_{\mathrm{x}}$ layer, and $\mathrm{T}$ indicates $-\mathrm{O},-\mathrm{OH}$ and -F.

Table S1. The force field parameters for $\mathrm{Ti}_{3} \mathrm{C}_{2} \mathrm{~T}_{\mathrm{x}}$ models in our simulations.

\begin{tabular}{ccc}
\hline Atom type & $\varepsilon / \mathrm{kcal}^{\mathrm{mol}}{ }^{-1}$ & $\sigma / \mathrm{nm}$ \\
\hline $\mathrm{T}_{\mathrm{i}}$ & 0.6087 & 0.19565 \\
$\mathrm{C}$ & 0.0660 & 0.35000 \\
$\mathrm{~F}$ & 0.1673 & 0.31430 \\
$\mathrm{O}$ & 0.1554 & 0.31656 \\
$\mathrm{H}$ & 0.0000 & 0.00000 \\
\hline
\end{tabular}

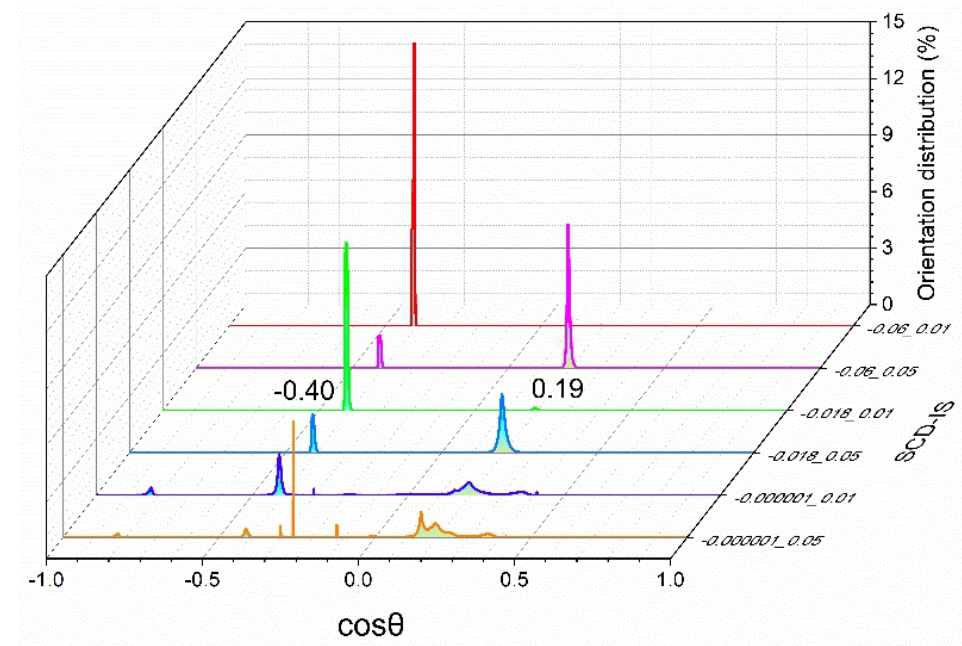

Figure S2. The orientation distributions of electric dipole on negatively charged surfaces under different surface charge densities $(\mathrm{SCD}=-0.000001,-0.018$ and -0.06$)$ and ionic strengths $(\mathrm{IS}=$ 
0.01 and 0.05 ) predicted by PTMC simulations.

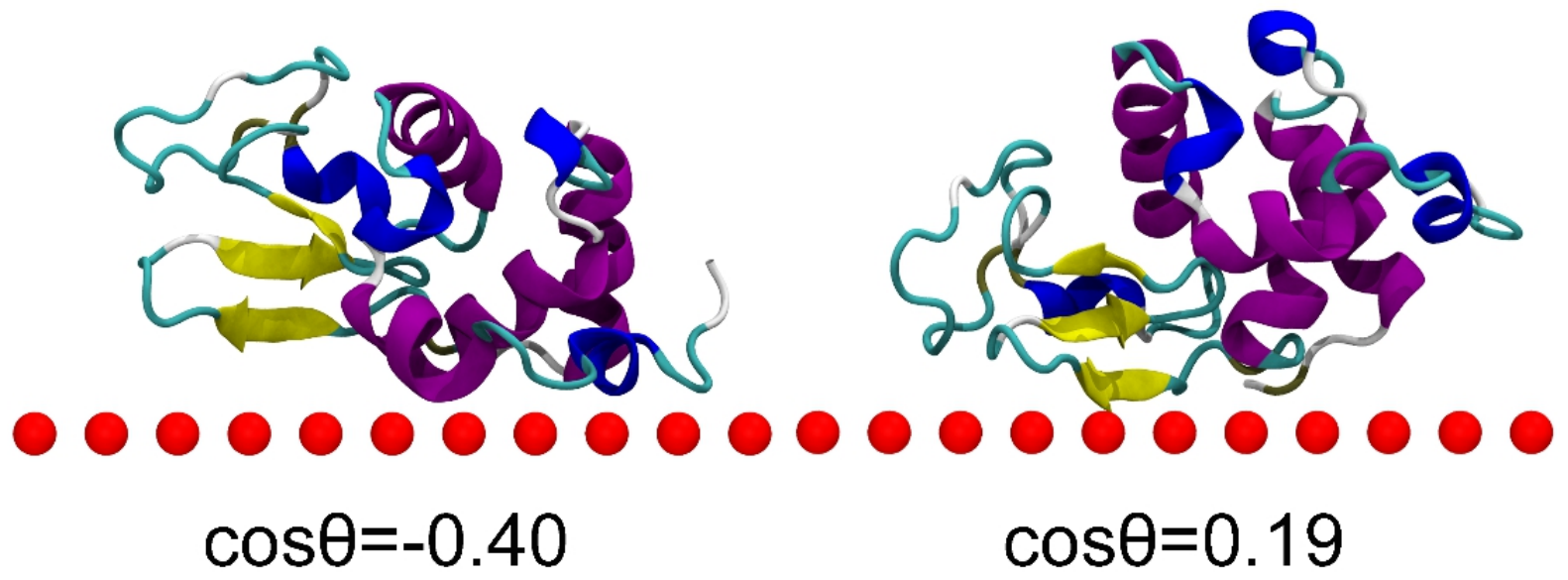

Figure S3. Preferred configurations of lysozyme orientations from PTMC simulations. The surface in red is for the negatively charged surface.

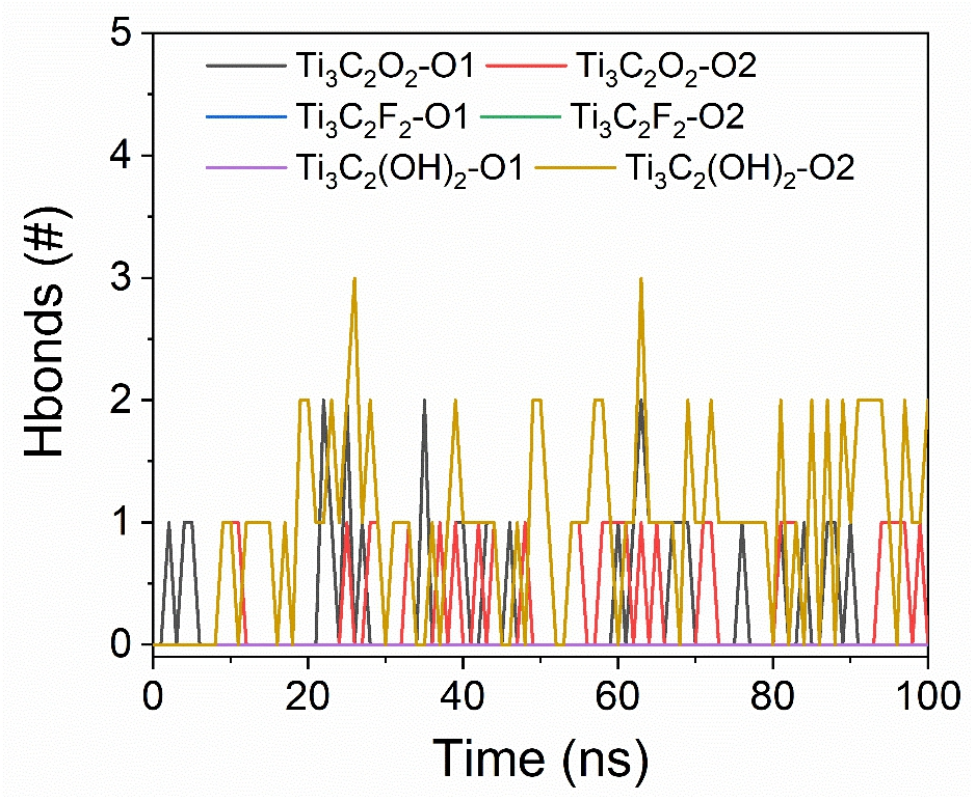

Figure S4. The hydrogen bonds between lysozyme and $\mathrm{Ti}_{3} \mathrm{C}_{2} \mathrm{~T}_{\mathrm{x}}$. 

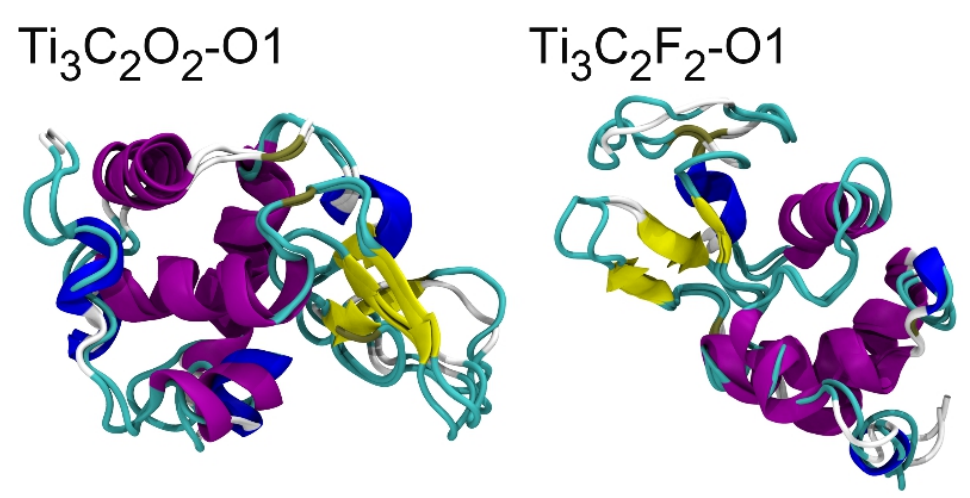

$\mathrm{Ti}_{3} \mathrm{C}_{2}(\mathrm{OH})_{2}-\mathrm{O} 1$

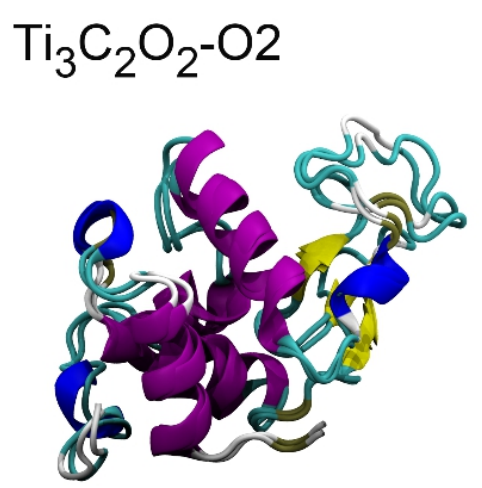

$\mathrm{Ti}_{3} \mathrm{C}_{2} \mathrm{~F}_{2}-\mathrm{O} 2$
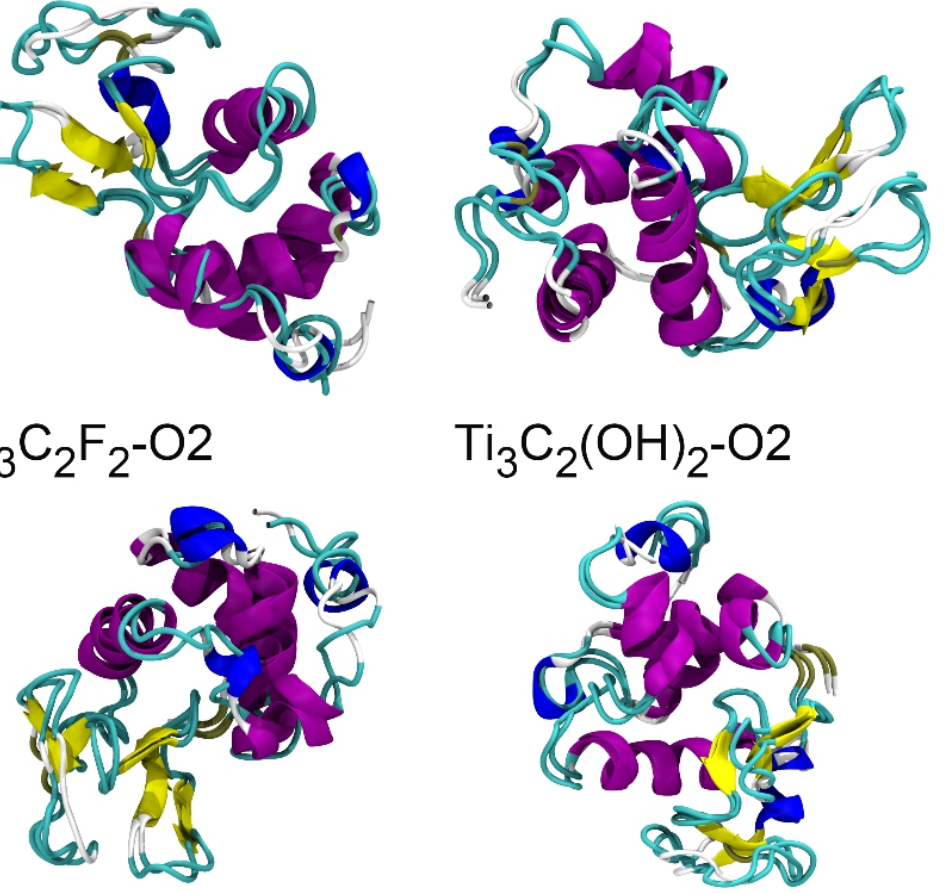

$\mathrm{Ti}_{3} \mathrm{C}_{2}(\mathrm{OH})_{2}-\mathrm{O} 2$

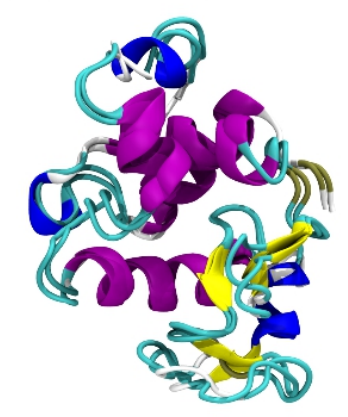

Figure S5. Structure superposition of lysozyme before and after MD simulations.

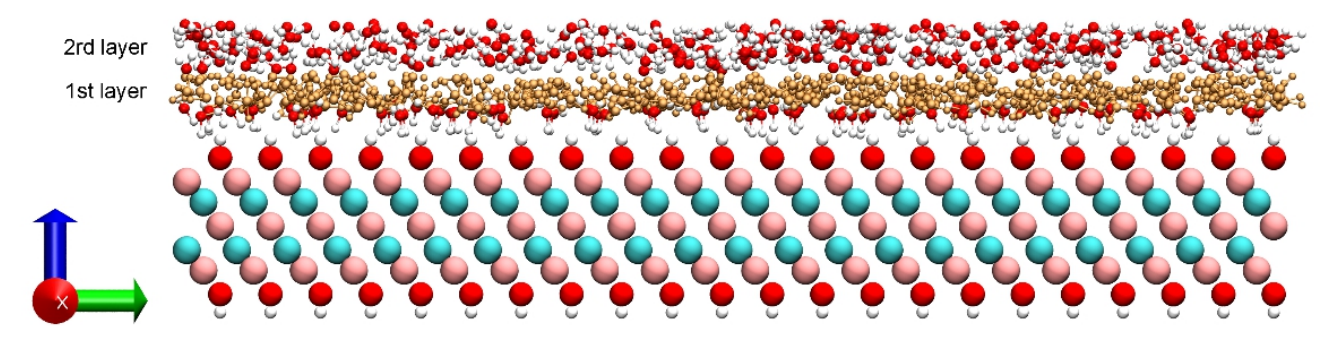

Figure S6. The corresponding water layers on the surface of $\mathrm{Ti}_{3} \mathrm{C}_{2}(\mathrm{OH})_{2}$. 

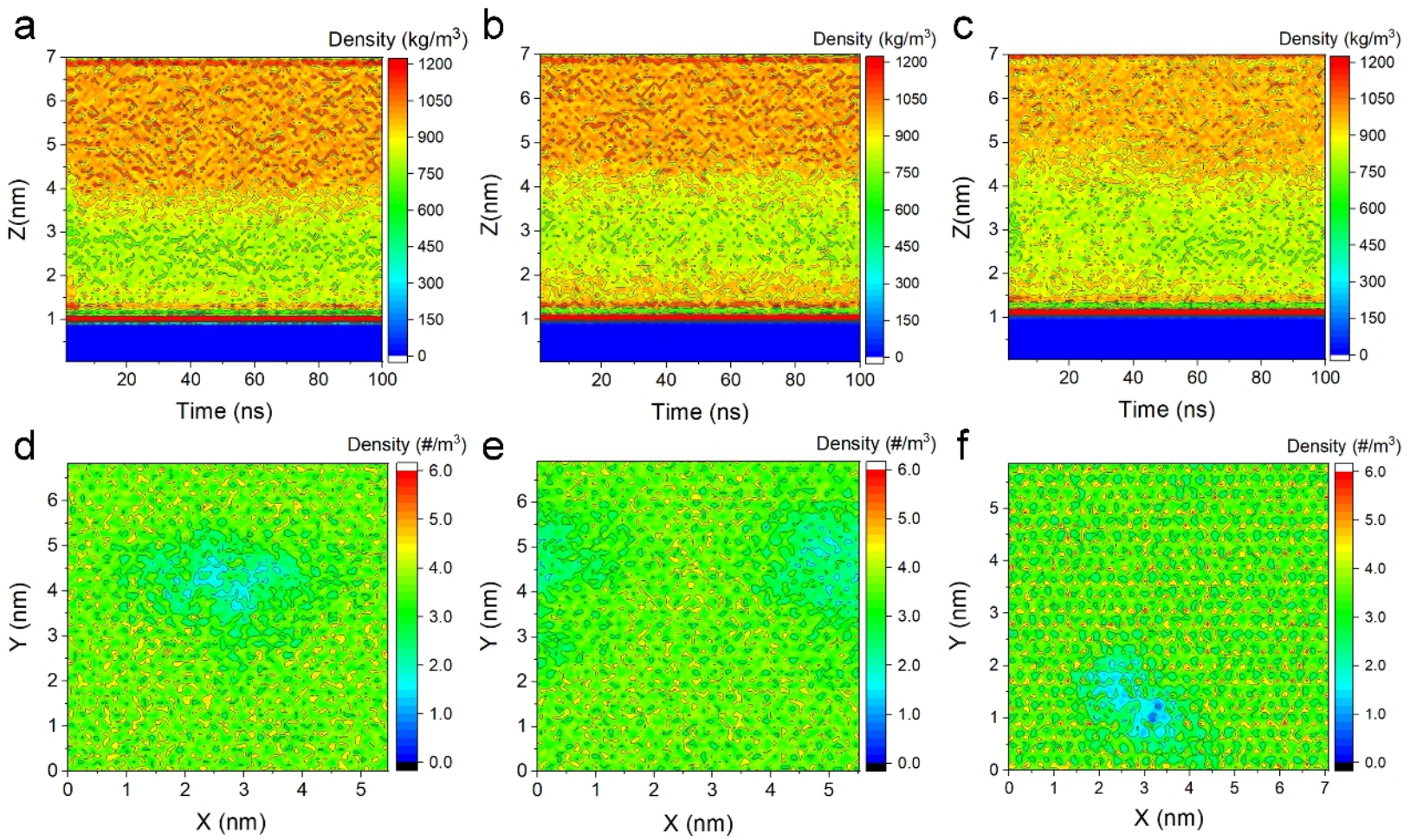

$\mathrm{Ti}_{3} \mathrm{C}_{2} \mathrm{O}_{2}$

$\mathrm{Ti}_{3} \mathrm{C}_{2} \mathrm{~F}_{2}$

$\mathrm{Ti}_{3} \mathrm{C}_{2}(\mathrm{OH})_{2}$

Figure S7. (a-c) The mass density distributions of water molecules along the z-axis during $100 \mathrm{~ns}$ MD simulations. (d-f) Density maps of the first water layer above different $\mathrm{Ti}_{3} \mathrm{C}_{2} \mathrm{~T}_{\mathrm{x}}$ surfaces. 